\title{
SUPERVIVENCIA Y ACTUALIDAD DE LA NOVELÍSTICA ESPERPÉNTICA DE VALLE-INCLÁN
}

\author{
Por \\ MIGUEL ENGUIDDANOS \\ Indiana University
}

Debemos sumar al castellano todos los modos del hablar español... Debemos ser todos uno. Todos una lengua. El Sol [Madrid], 8 de junio de 1932, p. 8. (Entrevista con Valle-Inclán)

¿Puede hablarse, hoy, en 1980, de "supervivencia y actualidad" de un arte de novelar practicado por un escritor muerto en 1936 ? ¿Perogrullada a la vista? Sí, claro que se puede hablar de la "supervivencia" de las obras maestras. ¿Qué novelista dejará hoy de tener en cuenta, consciente o subconscientemente, la obra de aquel otro novelista que murió no en 1936 sino en 1616? Sin ese enorme punto de referencia no podría hoy ni terminar nuestro novelador contemporáneo la primera página de su novela. ¿Ocurre lo mismo con ValleInclán? A mi me parece que sí. ¿Pero a qué viene mi pretensión, ahora y aquí, de "actualizar" lo logrado por Ramón del Valle-Inclán entre 1926 (fecha de Tirano Banderas) y 1928 (fecha de Viva mi dueño)? Para abrir lo que podría ser una fecunda polémica lo diré, nada más comenzar, lisa y llanamente:

El Valle-Inclán de las novelas esperpénticas está tan vivo que, al contemplar el panorama de la novela en español, hoy, se nos hace ya necesario incluirle. La novela española actual no puede compararse con los dos volúmenes y medio de El ruedo ibérico, y hasta la novela hispanoamericana de nuestra época no le hace tan siquiera puntas a Tirano Banderas.

La corte de los milagros se publica en 1927.' Ha alcanzado ya entonces Valle-Inclán el nivel más elevado de su arte en Tirano Banderas, de 1926. ¿Cómo escribe Valle-Inclán sus mejores novelas? Mucho se ha escrito y comentado sobre ello. A riesgo de repetir, vea mos con algún detenimiento un episodio de su celebrada novela. En el capitulillo IV del libro primero, "La rosa de oro" de La corte de los milagros, vemos que ha terminado la

1 Todas las citas de Valle-Inclán se refieren a la edición: La corte de los milagros. El ruedo iberico $I^{a}$ serie, $I$ (Madrid: Editorial Plenitud, 1944). 
ceremonia en que el nuncio papal le hace entrega a la reina de la Rosa de Oro, condecoración vaticana, y en él se nos da una primera visión de la reina Isabel II en su intimidad. ¿Cómo habla la reina de España - según Valle-Inclán-después y al margen de la solemne ceremonia? Sencillamente: como una chulapa de los barrios castizos de Madrid. Nos enteramos de que se siente ahogada por la opresión del corsé y del traje ceremonial: “...La Reina Nuestra Señora hubo de pasar a su camarín para aflojarse el talle [...] La Señora, al aflojarla la opresa cintura las manos serviles de la azafata, suspiró aliviándose..." (p. 14). En este gesto, que procede naturalmente de la imaginación creadora de Valle-Inclán, vemos humanizarse a la reina. Es lo que era en su más honda realidad: una señora aburguesada, abundante de carnes, no muy culta, cuyo madrileñismo castizo la acercaba en gestos y decires al pueblo llano. La presentación es magistral: la reina es simpática, buena y grotesca al mismo tiempo. Nos gana el corazón y nos hace reír al principio, pero poco después nos preguntamos con pena si semejante persona podía ser la reina de las Españas. Este efecto lo consigue Valle-Inclán en apenas dos páginas. Y ello se debe sin duda a la elección de un habla para su personaje que era-y hoy debería ser-familiar a los lectores. Tanto las expresiones de la reina, como las del narrador, provienen en gran parte de un mundo al que no se ha prestado atención minuciosa por considerarlo, la mayoría de los críticos, paraliterario. Lo extraño es que muchos de ellos han visto esta relación entre el habla de Valle-Inclán y sus personajes y la del mundo de los sainetes, zarzuelas y parodias: pero muy pocos le han prestado la debida atención. Incluso la comicidad de la acción de escenas como ésta en que la reina se afloja la cintura y se echa al coleto un trago de marrasquino, tiene sus raíces en el divertido ambiente del sainete. Lo que hace y dice la reina está armónicamente construido. El efecto que producirá en el lector es el que espera el artista: reconocimiento y sorpresa. ¡ La reina actúa y habla como una chulapa-o como una Isidra-..., pero es-oh, sorpresa-la reina de España! Simpática como muestra de humanidad, pero quizás inexcusable históricamente.

Pensemos que las primeras palabras que pronuncia Isabel II en la primera novela de El ruedo ibérico, o sea de toda la serie, son las siguientes: "Pepita, voy a confiarte un secreto. ¡Es para ti sola y no vayas a publicarlo por los desvanes!" $p$. 15). La reina "confía secretos" a una azafata, a una sirvienta que le afloja el talle, y le dice en el más castizo y rasgado estilo: “. . . no vayas a publicarlo por los desvanes..." Ante estas palabras, Doña Pepita Rúa, "pulcra y beatona", se "crispa". No quiere que la reina le cuente ningún secreto, dice, "porque hay duendes en Palacio". Si en el Palacio Real de Madrid hay desvanes y duendes--e indudablemente los había y los hay-, el mayestático gran edificio no se diferencia demasiado, no está tan lejos, de 
cualquier patio de vecindad madrileño, e incluso de cualquier "corrala" por humilde que sea. ¿A dónde nos lleva Valle-Inclán por ese camino? ¿Habrá, además de un palacio real, otro ideal? Ante las protestas de la azafata la reina dice: "- Haces bien [en callarte], porque eres un badajo cascado. ; Mira con lo que sales!"'(p. 15). Subrayo las dos expresiones por si a alguien se le pudiera escapar su traza vivaz y sainetera. Valle-Inclán narrador añade: “. . La Reina se abanicaba con aquel su garbo y simpatia de comadre chulapona" (p. 15).

Observo, al llegar a este punto, que casi todos los que hemos comentado páginas de Valle-Inclán semejantes, o relacionadas con ésta, sentimos la tentación de reproducir el texto por considerarlo definitivo y contundente, como si no necesitara glosa ni explicación y, la verdad, es que puede ser endiabladamente difícil de entender para quien no tenga un contexto de experiencia, o de lecturas, que le permita el acceso a lo que autor y personajes nos están diciendo en diferentes niveles de lenguaje. ${ }^{2}$

Hay, pues, que insistir en que la yuxtaposición de registros que van desde el lenguaje cortesano al plebeyo de Madrid son en Valle-Inclán artilugio poético y que una de las fuentes literarias que maneja el autor es indudablemente la expresividad del habla popular insertada en los demás contextos sociales del habla española. Volvamos otra vez al ejemplo: Sigue el relato de la escena en que doña Isabel se desahoga de estrecheces del talle y de secretillos con su camarera. "Isabel II abultaba con una sonrisa de pícaras mieles el belfo borbónico heredado del difunto Rey Narizotas: - Mira, dame un dedo de marrasquino. Se me borra la vista y creo que va a darme un vahido..."(p. 15). Decir “... abultaba con una sonrisa de pícaras mieles..." corresponde totalmente a la invención valleinclanesca: "abultaba" la sonrisa porque la reina era más bien obesa y carirredonda; pero "pícaras mieles", "belfo borbónico"y "Rey Narizotas" provienen del lenguaje popular. No sería difícil la comprobación en tonadillas, pliegos de cordel y panfletos pro y antiabsolutistas, tan abundantes en el siglo XIX. El tono del conjunto es decididamente sainetesco. Pero así como el sainete no plantea al espectador otra cosa que el hacerle reconocer alegremente la comicidad, y también los disparates, de la gente del pueblo, el texto de Valle-Inclán tiene una intención artística de más largo alcance. Al reconocer en el lenguaje, en este caso el de la Reina de España, las deficiencias y las gracias de su pueblo, obliga al lector a

\footnotetext{
2 Dice Julián Marías a este respecto en un excelente comentario a La corte de los milagros: “. . La mezcla de 'registros' lingǘsticos introd uce una pluralidad de perspectivas en un párrafo que pinta una escena. Las diferencias de 'potencial' de los vocablos y los giros hacen pasar corrientes eléctricas por la prosa; el empaque se junta con la rechifla y descalifica, sin decir nada, la pretensión: lo que en una línea se afirma se destruye en la siguiente, sólo con cambiar de tono, dejando en pie, pero ya invalidada, la línea anterior... "Valle-Inclán en El ruedo ibérico (Buenos Aires: Editorial Columba, 1967).
} 
leerlo desgarradamente. Los polos de la tensión existencial son "pueblo" y "Reina", es decir quien obedece y quien manda. Quizás el que obedece no esté muy dispuesto a hacerlo porque el que-o la que-manda no está en el trono espiritual que le corresponde. Su presencia en el trono es una constante, aunque inconsciente, abdicación. El personaje Reina Isabel es, también, paradigma de contrastes y tensiones. En su realidad achulapada, Valle-Inclán no nos permite olvidarnos que el trono que ocupa la Reina es el del rey conquistador y santo, Fernando III, y lo es también el de Alfonso XIII, nieto de la reina Isabel y contemporáneo de Valle-Inclán. Y hoy podríamos añadir: también el de Juan Carlos I. . . Así pues, la gracia primera de la chulapería se nos amarga en el paladar al poner juntos habla pícara y zarrapastrosa y trono sagrado y reverencial. También es cierto que esa angustiosa realidad histórica está proyectada por Valle-Inclán hacia el presente de los años en que escribe La corte de los milagros y hacia el pasado del que viene la desdichada situación isabelina. Puede decirse que, implícitamente, Valle apunta también hacia el porvenir y quizás hasta nuestro presente, aunque el hecho de que la distancia en el tiempo vaya anulando la eficacia de las claves necesarias para descifrar el texto haga problemática dicha proyección.

En la descripción de la escena de La corte de los milagros, el narrador usa también el procedimiento de la construcción tensa repetidas veces. Tensión entre el deber ser de la reina y el ser vulgar: "La Reina Nuestra Señora extasiaba el claro azul de sus pupilas sobre la pedrería de las manos, y un suspiro feliz deleitaba sus crasas mantecas" (p. 16) La paradoja, grotesca y dramática al mismo tiempo, está perfectamente establecida en tres niveles de expresividad: (1) "claro azul de sus pupilas", nivel alto; (2) nivel intermedio: "pedrería de las manos" — no dice joyería; y (3) nivel inferior: "sus crasas mantecas"-expresión de rompe y rasga. La reina llama "tarambana" a doña Pepita y, por fin, pasa a contarle su secreto: ha decidido corresponder a la bondad del Papa, que le ha otorgado la Rosa de Oro, enviando una cantidad de dinero para la limosna de San Pedro: "-Pues he pensado mandar un millón de reales para la limosna de San Pedro. ¿Te parece que será poco? Yo, francamente, no sé lo que puede hacerse con esos cuartos" (p. 16) Sigue la chulapería: la reina quiere "corresponder" al Santo Padre. Quiere, como dirá pocas páginas después, "quedar bien". Habla castizamente de "cuartos" y Valle-Inclán pone de relieve su inconsciencia-pecado histórico-mortal de Isabel II - al hacerle decir al personaje que no sabe lo que se puede hacer con ellos. Sigue el diálogo divertido y grotesco: "Reflexionó la Doña Pepita, con los ojos en el techo de amorcillos: - Con un millón, bien se hace una casa. - ¡No, mujer! Se harán muchas. —Casitas pequeñas. Yo hablaba de una casa de renta, una casa como las del barrio. - Y tú, grandísima tonta, ¿crees que un millón no da para más misas?"(p. 16). La manera de tratar la reina el millón y 
esta última frase, subrayada por mí, no pueden ser más saineteras. Siguen reina y azafata hablando del asunto y ésta dice que Paco Veguillas, "el barbero de Su Majestad el Rey Don Francisco"se había comprado "... un cascajo en la calle de la Cabeza". La reina responde: "...- ¿Conque compró una casa? Mucho se gana rapando barbas de papanatas" (p. 16). Si concentramos nuestra atención en la frase "rapando barbas de papanatas", enmarcada por toques vívidos y divertidos como "la Doña Pepita", "una casa como las del barrio", "¿crees que un millón no da para más misas?", podemos advertir el dejo de familiaridad entre este lenguaje y el de los personajes de sainete; pero la gracia, y la trascendencia, de la situación creada por Valle-Inclán deriva de un gran acierto: el "papanatas" es el rey consorte, la que dice "dar para más misas" es la reina, el "barrio" son los hermosos aledaños del Palacio Real de Madrid. Los personajes de este "sainete" son los máximos protagonistas de la tragedia histórica española.

Pero no se crea que el secreto último del arte de Valle-Inclán consiste simplemente en utilizar con éxito las expresiones populares del sainete o de la vida en torno suyo. No, su verdadera Gracia, con mayúscula, estriba en el montaje bien estructurado, en poético contrapunto, del lenguaje saineteril y popular, con el lenguaje y la visión poéticos de los que él era maestro. He dicho ya en otra ocasión que el arte de Valle-Inclán era más reconfigurador que deformador. ${ }^{3}$ La visión en espejos cóncavos y convexos de la vida española-e hispanoamericana-era sólo un punto de partida. Como en los iconos y retablos (recuérdese que el libro primero de Tirano Banderas se titula "Icono del tirano"), paralelamente a los hallazgos visuales del cubismo (recordar: "... Rotura de la pista en ángulos. Visión cubista del circo Harris"), ValleInclán nos ofrece una nueva manera de yuxtaponer diversos niveles del lenguaje en la novela. A mi modo de ver, la más adelantada en español, hasta hoy. Difícil es escoger un episodio cualquiera, pues la primera novela de la serie de El ruedo ibérico no tiene desperdicio. La reina que se afloja el corsé, habla como una chulapa, cuenta en reales, es devota de la Virgen de la Paloma y se muestra preocupadísima "por quedar bien" con el Santo Padre, que la acaba de distinguir con la Rosa de Oro. Los "pollos de la goma" aparecen en otra página, robando capas y tirando a un guardia por la ventana. La monja milagrera y farsante... La serie de amantes de la reina, o "pollos reales"... No hay página ilegible. El conjunto es genial. Al terminar su lectura podríamos caer en la trampa de creernos regocijados por la enorme gracia de las estampas valleinclanescas, que la tienen. Pero a la vez sentimos un regustillo amargo, una anticipacaión de futuras tragedias y una lástima inmensa por ese pobre pueblo español. Y esto lo logra Valle-Inclán sin la más

\footnotetext{
${ }^{3}$ Miguel Enguídanos, "Raíces históricas del esperpentismo", Insula, No. 305 (abril de 1972).
} 
mínima concesión al sentimentalismo y sin la más mínima idealización de su pueblo.

En el proceso de reconfiguración de los personajes históricos de La corte de los milagros ninguno más grotesco, ni más marioneta, que el rey consorte don Francisco de Asís. El personaje de carne y hueso parecía estar ya "hecho" para "estar" en la novela de Valle-Inclán. La reina, que lo desprecia, lo usa en la novela como alfiletero, o acerico, de sus burlas. Es decir, que es el personaje superesperpéntico; pues doña Isabel, esperpento ella misma, esperpentiza a su marido. Le llama Paquita. Se ríe de él ante sus damas, canta coplas escatológicas, dice que lleva en su ropa interior más encajes que las mujeres, y que orina en cuclillas. En fin, presentado del modo literario como lo hace Valle-Inclán, es el personaje que simboliza la degradación máxima de ser hombre y de ser rey. Es el personaje que ha tocado fondo. No puede ya caer más bajo. Sin embargo, Valle no ha escatologizado a don Francisco de Asís por burlarse de él, como en su tiempo había hecho todo Madrid. Hay una cierta intención histórico-realista: es que don Francisco era así. Ah, pero el genio de Valle-Inclán va mucho más lejos. Resulta, a la fin y a la postre, que el títere grotesco va a ser utilizado por el autor para cerrar estructural e ideológicamente la novela y darle su cabal sentido y trascendencia. Habla don Francisco con el primer ministro González Bravo, que ha ido a cumplimentarle, según la etiqueta palaciega. Ha muerto el general Narváez, el último espadón de aquel reinado, y se presienten, se temen o se desean, cambios trascendentales en España. Exclama el rey consorte, entre otras cosas:

... Se ha omitido consultarme para la provisión de cargos en Palacio. Se ha querido, sin duda, con esa actitud, ultrajar mi dignidad de esposo, mayormente cuando mis exigencias no son exageradas. Que Isabelita no me ame es muy explicable ... Yo la disculpo, porque nuestro enlace no dimanó del afecto y ha sido parto de la razón de Estado. Yo soy tanto más tolerante cuanto que yo tampoco he podido tenerla cariño. Nunca he repugnado entrar en la senda del disimulo y siempre actué propicio a sostener las apariencias para evitar un desagradable rompimiento ... Pero Isabelita, o más ingenua o más vehemente, no ha podido cumplir con este deber hipócrita, con este sacrificio que exigía el bien de la Nación. Yo me casé porque debía casarme ... Porque el oficio de Rey lisonjea [...], acepté con el propósito de ser tolerante para que lo fueran igualmente conmigo. ¿Y qué consideración se me guarda? No hablo sólo por mí. Esos nombramientos van a escandalizar en la Nación. ¿La Nación no puede tolerar dignamente el espectáculo y el escarnio que se hace del tálamo! [ ...] La Reina, con su conducta, se hace imposible a mi dignidad y a la del pueblo español. (pp. 370-371) $)^{4}$

\footnotetext{
${ }^{4}$ Estas palabras de Don Francisco de Asís, rey consorte de España y personaje de La corte de los milagros, parece ser que fueron, casi textualmente, no dichas sino escritas en realidad. Ver Pedro de Répide, Isabel II, reina de España (Madrid: Espasa-Calpe, 1932). Dice Répide que existe una
} 
El juego literario es perfecto: hay una hora de la verdad que a todos nos llega. Valle-Inclán no nos ha engañado, así es la vida, así es el hombre. Por eso está vivo el escritor. Por eso está viva su novela: En España se suele decir que los niños y los locos dicen la verdad. Valle-Inclán cierra su primera novela de El ruedo con palabras terribles: ¡la nación!, ¡la dignidad!, ¡el escarnio que sufre el pueblo español! ¡ No tolerarlos, no tolerarlos!, le hace decir a su pobre pelele coronado. ¿Quién dice hoy en España, o en las Españas, cosas semejantes? Hay, sí, hijos literarios de Valle-Inclán. Conocemos a varios. Pienso que sería estupendo tener hoy entre nosotros al gran y buen don Ramón. Triste es que se nos muriera en 1936; pero no, lo mejor de él no está muerto. Está ahí, para siempre, en sus libros incomparables. Extrañas, terribles, son las visiones históricas de Valle-Inclán. Difíciles de explicar en su más hondo significado. Una vez vistas-leídas-, son imborrables. Algo en nosotros, quizá lo más falso, se empequeñece. iGran catarsis para españoles e hispanohablantes de todas clases! Parecen hoy más frescas y válidas que cuando se escribieron. Van al hondón de la condición humana. Antonio Machado lo reconoce así en un bien conocido poema:

Yo era en mis años, don Ramón, viajero

de áspero camino, y tú Caronte

de ojos de llama, el fúnebre barquero

de las revueltas aguas de Aqueronte.

No tenemos hoy-y estoy seguro de que concurren en ello escritores y críticos hispanos-mejor Caronte, mejores ojos incandescentes, ni mejor barquero en las turbias aguas del océano que nos rodea en este cuarto final del siglo XX.

carta de Don Francisco dirigida al ministro de la gobernación, Benavides, que es casi literal. Valle-Inclán debió conocer el documento. Esto plantea un nuevo problema sobre las fuentes o raíces de Valle-Inclán.

5 Antonio Machado, "A Don Ramón del Valle-Inclán”, Obras. Poesía y prosa (Buenos Aires: Editorial Losada) 1964, p. 277. 
